\title{
COMPARISON OF LASER ABLATION AND SPUTTER DESORPTION OF CLUSTERS FROM AU $\mathrm{CU}_{5} \mathrm{AL}_{4}$
}

${ }^{1}$ B.V. King, ${ }^{2,3}$ J.F. Moore, ${ }^{3}$ Y.Cui,${ }^{4}$ I.V. Veryovkin, ${ }^{4}$ C.E. Tripa

\begin{abstract}
Ionised and neutral clusters were desorbed from spangold, a polycrystalline ternary alloy with composition $\mathrm{Au}_{7} \mathrm{Cu}_{5} \mathrm{Al}_{4}$, using both a femtosecond laser beam and an energetic ion beam and the resulting time of flight mass spectra compared. Neutral clusters containing up to 7 atoms were ejected by the $15 \mathrm{keV} \mathrm{Ar}^{+}$beam whereas only smaller positively and negatively charged clusters were observed from the laser ablated spangold surface.

Laser ionisation mass spectrometry (LIMS) positive ion spectra were dominated by Al containing cluster ions whereas $\mathrm{Au}$ containing ions dominated the negative LIMS spectrum. An odd-even variation in LIMS cluster yield was observed, consistent with previous results and due to fragmentation of photoionised clusters. The laser sputtered neutral mass spectrometry (laser SNMS) spectrum showed that larger desorbed clusters were gold rich. The cluster signals also followed a power law dependence with cluster size with the exponent value of 6-7.6 for sputtered mixed clusters being greater than that found from sputtering of pure elements, similar to the result found previously in the $\mathrm{Cu}$ $\mathrm{Au}$ system.
\end{abstract}

2

(C) 2014. This manuscript version is made available under the Elsevier user license http://www.elsevier.com/open-access/userlicense/1.0/ 
PACS 61.80.Jh, 61.82.Bg, 68.49.Sf, 61.80Ba

KEYWORDS Sputtering; clusters; laser ablation; LIMS; SNMS; photoionisation 


\section{INTRODUCTION}

The desorption of atoms and atomic clusters from surfaces under energetic ion and laser impact is the basis for several important surface analytical techniques [1,2]. For example, kiloelectronvolt ion impact is used in secondary ion mass spectrometry (SIMS) and sputtered neutral mass spectrometry (SNMS) [3] whereas laser ablation is used in techniques such as laser ablation inductively coupled plasma mass spectrometry, LA_ICPMS, and laser ionization mass spectrometry, LIMS [4]. In this paper, we compare analysis of an alloy using a version of SNMS, laser SNMS, which uses a laser beam to ionize neutrals desorbed from the surface, to analysis by LIMS.

Review papers, eg [5,6], have detailed the general differences between these sputter and ablation techniques for surface analysis, although it should be noted that laser SNMS is referred to in [5] by the acronym SALI. Laser SNMS is however a more complicated technique, requiring both laser and ion beams for analysis, in comparison to LIMS where only a laser beam is required. Both LIMS and laser SNMS are sensitive, allowing sub ppm analysis, but LIMS suffers from the large variation in relative sensitivity factors $\left(10^{2}\right.$ $\left.-10^{6}\right)$ compared to laser SNMS (0.3 - 3) [6]. Sputtering techniques are capable of more quantitative depth profiling, since laser ablation suffers from shot-to-shot intensity variation, but laser ablation can remove material more quickly, up to microns per shot compared to $\mathrm{nm}$ for a sputter beam.

In all these techniques, signals may come from desorbed atoms or clusters of atoms. Measurement of the mass spectra of desorbed clusters is important for the analysis of organic surfaces since fingerprint spectra can be used to detect molecular information. But information of basic processes of particle desorption are best found by analysis of simpler systems. We have therefore previously $[7,8]$ shown that large neutral clusters, containing up to 30 atoms, may be desorbed from metal binary alloy surfaces by ion beam sputtering and SNMS analysis. The relative yield of the neutral clusters of $\mathrm{n}$ atoms, $\mathrm{Y}_{\mathrm{n}}$, has been shown to be given by a power law

$$
\mathrm{Y}_{\mathrm{n}} \sim \mathrm{n}^{-\delta}
$$


where $\delta$ was found to be monotonically related to the total sputter yield [9]. This observation means that elements with higher sputter yields were more likely to eject high mass clusters and so have a lower value of $\delta$. The yield of ejected clusters depends on their internal energy immediately after the desorption event as well as the stability of the cluster. If the internal energy is high, the cluster is likely to undergo a cascade of unimolecular decompositions as it leaves the surface. Such decompositions determine the value of $\delta$. In contrast, for secondary ion analysis, the yield of clusters leaving in an ionized state depends on electron transfer between the cluster and surface as the particle leaves the surface which in turn depends on the relationship between the electronic energy levels in the perturbed surface and the cluster. If laser ablation is used in conjunction with secondary ion measurement, then the cluster yield may also depend on the laser parameters, because ionization also occurs in the plume of the ablated material. In particular, fragmentation of clusters is known to be reduced using femtosecond lasers [2]. The previous review papers do not however explicitly consider the variation in intensity from ejected clusters. It is then of interest to compare LIMS and laser SNMS of the same surface to see whether the variation of yield with cluster size is the same for both techniques. The results of this study will show that the variation of cluster intensity with mass is qualitatively similar for the two techniques although the signal from the laser SNMS experiment is much higher than that from the LIMS experiment.

\section{EXPERIMENTAL}

Experiments used polished polycrystalline samples of pure $\mathrm{Cu}$ and spangold, $\mathrm{Au}_{7} \mathrm{Cu}_{5} \mathrm{Al}_{4}$. Laser ablation experiments were carried out at UIC using a Spectra Physics Tsunami laser producing $65 \mathrm{fs}$ pulses at a $1 \mathrm{kHz}$ repetition rate. Three different laser intensities for analysis were used corresponding to pulse energies of 2, 4 and $6.5 \mu \mathrm{J} /$ pulse with an oval beam spot of dimensions $6 \mu \mathrm{m} \times 30 \mu \mathrm{m}$. The sample was ablated to clean the surface before the spectrum was acquired. A $1 \mathrm{mmx} 1 \mathrm{~mm}$ area was cleaned prior to analysis and ablated positive and negative ions were accelerated into a TOF analyser. A fuller description of the experimental setup is given in [10]. 
The laser SNMS experiments were carried out at Argonne National Laboratory on the SARISA instrument [3]. A $300 \mathrm{~ns} 15 \mathrm{keV} \mathrm{Ar}^{+}$beam was used to erode the target and desorbed neutral clusters were ionized using 50-500 $\mu \mathrm{J}$ pulses of $157 \mathrm{~nm}$ light at varying intensities from a GAM $F_{2}$ laser. The photoions were then extracted into a reflectron TOF analyzer which had a resolving power of 2100 at mass 421. The ion and laser pulsing scheme was optimized to detect large clusters by putting a $4 \mu$ s delay between the end of the ion pulse and the start of the laser pulse. However, the use of a low extraction voltage $(1 \mathrm{kV})$ precluded measuring ions with masses above 1000 Da. Spectra were obtained in both analog and counting modes since analog mode is appropriate at high count rates whereas counting mode is appropriate for low count rates. A composite spectrum was determined by equating the spectra for a specific intermediate peak.

The intensities of larger clusters in the laser SNMS experiment were found to increase linearly with pulse energy, a signature of a single photon ionisation process since, for such a process, the photoion signal, $\mathrm{S}$, varies with laser intensity, $\mathrm{P}_{\mathrm{L}}$, as [11]

$$
\mathrm{S}=\mathrm{S}_{\mathrm{sat}}\left(1-\exp \left(-\sigma \mathrm{P}_{\mathrm{L}} \Delta \mathrm{t} / \mathrm{h} v\right)\right)
$$

where $\mathrm{S}_{\mathrm{sat}}$ is the signal intensity at saturation, $\sigma$ is the photoabsorption cross-section, $\mathrm{h} v$ is the laser photon energy of $7.89 \mathrm{eV}$ and $\Delta \mathrm{t}$ is the laser pulse width of $10 \mathrm{~ns}$. Saturation of the signal was not reached at the highest laser power so the signal for individual clusters could vary with $\sigma$. However we have previously found $\sigma$ to be relatively constant for smaller clusters sputtered from $\mathrm{Cu}-\mathrm{Au}$ and $\mathrm{Al}-\mathrm{Au}$ surfaces, so the measured photoionization signal was assumed to be proportional to the cluster intensity.

The vacuum during analysis was better than $1 \times 10^{-9}$ mbar and the surface ion beam cleaned before spectra were acquired.

\section{RESULTS AND DISCUSSION}

The laser ablation (LIMS) spectra (fig. 1) show clusters up to $600 \mathrm{Da}$ are ablated. Overall, the ion yields for both positive and negative spectra are similar. The negative ion 
spectrum is dominated by the monomers $\mathrm{Al}, \mathrm{Cu}$ and especially $\mathrm{Au}$ but $\mathrm{AuCu}, \mathrm{Au}_{2} \mathrm{Al}$ and $\mathrm{Au}_{2} \mathrm{Cu}$ are also prominent. The positive ion spectrum shows a weaker Au signal but more clusters in the $200-500 \mathrm{Da}$ mass range and evidence of $\mathrm{Au}_{2}$ and $\mathrm{Au}_{3}$. The laser SNMS spectrum (fig. 2) in counting mode shows peaks up $1000 \mathrm{Da}$ for elemental clusters of $\mathrm{Au}-$ $\mathrm{Au}_{5}, \mathrm{Cu}-\mathrm{Cu}_{4}$ but $\mathrm{Al}$ clusters apart from $\mathrm{Al}_{3}$ could not be uniquely identified from the spectra. There were also smaller contributions from mixed oxide clusters involving $\mathrm{Al}$ including $\mathrm{AlO}, \mathrm{Al}_{2} \mathrm{O}, \mathrm{AuAl}_{2} \mathrm{O}_{2}, \mathrm{AuAl}_{2} \mathrm{O}, \mathrm{AuAl}_{2} \mathrm{O}, \mathrm{Au}_{2} \mathrm{CuAlO}$, and $\mathrm{AuCuAlO}_{2}$. The overall signal levels/laser pulse from the laser SNMS spectra are much higher than those from LIMS, indicating that the ionization cross-section is much higher for the laser SNMS compared to LIMS. The variation with laser intensity of the laser SNMS signal for larger mixed clusters was sublinear, indicating from eqn. 2 that the clusters were ionized with a single photon but that the signal had not saturated.

Fig. 3 shows the LIMS spectrum from laser ablated $\mathrm{Cu}$ sample. Overall the positive ion signal decreases with cluster size according to a power law as in eqn. 1 with $\delta=3.9$. Superimposed on this power law dependence is an odd-even variation with $\mathrm{Cu}_{\mathrm{n}}{ }^{+}$clusters with even $n$ having lower intensities than odd $n$ clusters. A similar variation has been seen in previous SNMS measurements and related to preferential decay of the even $\mathrm{Cu}_{\mathrm{n}}^{+}$ clusters with have lower binding energies than the odd $n$ clusters. The value of $\delta$ is similar to a previous value of 3.82 found from SNMS of a pure $\mathrm{Cu}$ sample.

We have shown that the mass spectrum of clusters ejected from metal alloy surface in SNMS experiments is related to the probability of randomly forming clusters of a given composition [8], so mixed clusters become more probable as the number of atoms in the cluster increases. For the ternary alloy, $\mathrm{Au}_{7} \mathrm{Cu}_{5} \mathrm{Al}_{4}$, we would expect the probability of randomly desorbing a $\mathrm{n}$ atom cluster $\mathrm{Au}_{\mathrm{x}} \mathrm{Cu}_{\mathrm{y}} \mathrm{Al}_{\mathrm{z}}$ to be

$$
P(x, y, z)=\frac{n !}{x ! y ! z !}(7 / 16)^{x}(5 / 16)^{y}(4 / 16)^{z}
$$


where $\mathrm{n}=\mathrm{x}+\mathrm{y}+\mathrm{z}$ and the fractions represent the composition of the elements in the alloy surface. Note that the spectra were measured after eroding the surface to equilibrium so the desorbed fluxes are proportional to the bulk alloy composition. Combining eqns. 1 and 3, the overall intensity, I, of the signal from a desorbed $\mathrm{Au}_{\mathrm{x}} \mathrm{Cu}_{\mathrm{y}} \mathrm{Al}_{\mathrm{z}}$ cluster in the limit of random particle ejection is then

$$
I \propto P(x, y, z)(x+y+z)^{-\delta}
$$

To investigate the power law dependence of cluster emission the measured cluster intensities have been scaled by dividing by the factor $\mathrm{P}(\mathrm{x}, \mathrm{y}, \mathrm{z})$ calculated from equation 3 . Given the large variation in cluster intensities with $\mathrm{n}$ and composition, the measured data have been further scaled by taking the fourth root of the signal in order to improve visibility of the larger clusters in the ternary composition diagrams shown in figs 4 to 6 . Fig. 4 shows that Al containing clusters are more prominent in the positive LIMS spectrum whereas $\mathrm{Au}$ containing clusters are preferentially measured in the negative LIMS spectrum (fig. 5). Such a result is expected due to the tendency of $\mathrm{Al}$ and $\mathrm{Au}$ to form positive and negative ions respectively.

The SNMS spectrum (fig. 6) shows many more clusters than the LIMS spectra. If the cluster composition reflected the bulk spangold composition, an even scatter of points over the entire composition triangle would be expected. This is not the case, with higher intensities observed for gold rich clusters, especially for the larger clusters. This finding agrees with previous measurements in the $\mathrm{Au}-\mathrm{Cu}$ and $\mathrm{Au}-\mathrm{Al}$ binary alloy systems where the larger ejected clusters were found to be predominantly gold rich. This result has been explained by the known preferential enrichment of gold in the near surface region under ion irradiation [12]. Since larger ejected cluster become progressively enriched in atoms from beneath the surface, they would be expected to become progressive gold rich.

Figs 7 and 8 show the relative SNMS yield from binary and ternary clusters as a function of cluster size. The lack of dynamic range in the SNMS measurements precludes precise measurements of $\delta$ from this data. However the data in fig. 7 is consistent with a power 
law relationship between intensity and cluster size with $\delta$ in the range from $6\left(\mathrm{Au}_{\mathrm{n}} \mathrm{CuAl}\right)$ to $7.6\left(\mathrm{Au}_{\mathrm{n}} \mathrm{CuAl}_{2}\right)$. The signal for $\mathrm{Au}_{\mathrm{n}}$ clusters in fig. 8 varies as $\mathrm{n}^{-3.7}$, a similar variation than found previously [7] $(\delta=2.83)$ for $\mathrm{Au}_{\mathrm{n}}$ sputtered from pure Au but less than $\delta=6.5$ for $\mathrm{Au}_{\mathrm{n}}$ sputtered from $\mathrm{CuAu}$ alloys of similar $\mathrm{Au}$ composition to spangold. In general of the values of $\delta$ for mixed clusters sputtered from spangold are higher than $\delta$ values for the sputtered individual elements, as was found for the $\mathrm{Cu}-\mathrm{Au}$ system [7]. The increased yield of $\mathrm{Au}_{\mathrm{n}} \mathrm{Al}_{\mathrm{m}}$ clusters compared to $\mathrm{Au}_{\mathrm{n}} \mathrm{Cu}_{\mathrm{m}}$ cluster in fig. 7 is consistent with the higher binding energies of the $\mathrm{AuAl}$ clusters compared to the $\mathrm{AuCu}$ clusters. Density functional theory calculations [13] of binary and ternary cluster binding energies showed that $\mathrm{Al}_{2} \mathrm{Au}$ and $\mathrm{AlAu}$ clusters had binding energies of $5.8 \mathrm{eV}$ and $3.81 \mathrm{eV}$ respectively, greater than the $\mathrm{Au}-\mathrm{Cu}$ binding energy of $2.71 \mathrm{eV}$.

\section{CONCLUSION}

Laser ionization mass spectrometry and sputter neutral mass spectrometry measurements were made on $\mathrm{Au}_{7} \mathrm{Cu}_{5} \mathrm{Al}_{4}$. The variation of ion yield with cluster size was similar for the two techniques, although the signal was much higher and many more clusters could be identified with the laser SNMS technique. LIMS positive ion spectra were dominated by Al containing cluster ions whereas $\mathrm{Au}$ containing ions dominated the negative LIMS spectrum. An odd-even variation in cluster yield was observed, consistent with previous results and due to fragmentation of photoionised clusters. The laser SNMS spectrum showed that larger desorbed clusters were gold rich. The cluster signals also followed a power law dependence with cluster size with the exponent value for sputtered mixed clusters being greater than that found from sputtering of pure elements, similar to the result found in the $\mathrm{Cu}-\mathrm{Au}$ system.

\section{ACKNOWLEDGEMENTS}

This work is supported by the U.S. Department of Energy, BES-Materials Science, under Contract W-31-109-ENG-38. The authors thank Madelynne Herbetson for assisting with analysis. 


\section{REFERENCES}

1. Y.Lin, Q.Yu, W. Hang, B. Huang, Spectrochinica Acta B65 (2010) 871

2. J Pisonero, B Fernandez, D Guenther, J. Anal. At. Spectrom. (2009) 1145

3. I.V. Veryovkin, C.E.Tripa and M.J. Pellin M J, Phys. Proc. 1379 (2008)

4. M. Bolshov in "Surface and Thin Film Analysis: Principles, Instrumentation, Applications", (H Bubert and H Jenett eds, Wiley-VCH Verlag GmbH, 2002) 231240.

5. J. S. Becker, H.-J. Dietze, Fresenius J Anal Chem 346 (1993) 134

6. J. S. Becker, H.-J. Dietze, Int. J. Mass. Spectrom. 197 (2000) 1

7. B.V. King, J.F. Moore, A. V. Zinovev, I.V. Veryovkin, M.J. Pellin, Nucl. Instr. Meth.B 267, 2757 (2009)

8. B.V. King, J.F. Moore, I.V. Veryovkin, M.J. Pellin, Nucl. Instr. Meth.B 317, 115 (2013)

9. A. Wucher, Mat.Fys.Medd.Dan.Vid.Selsk. 52 (2006) 405

10. Y. Cui, J.F. Moore, S Milasinovic, Y Liu, R.J. Gordon, L Hanley, Rev Sci Instrum 83 093702 (2012)

11. VS Lethokov, "Laser Photoionisation Spectroscopy”, Academic Press NY, 1987

12. V.I. Zaporozchenko, M.G. Stepanova, Prog. Surf. Sci., 49 (1995), 155

13. D.R. Belcher, M.W. Radny, B.V. King, Mater. Trans. 48 (2007) 689. 


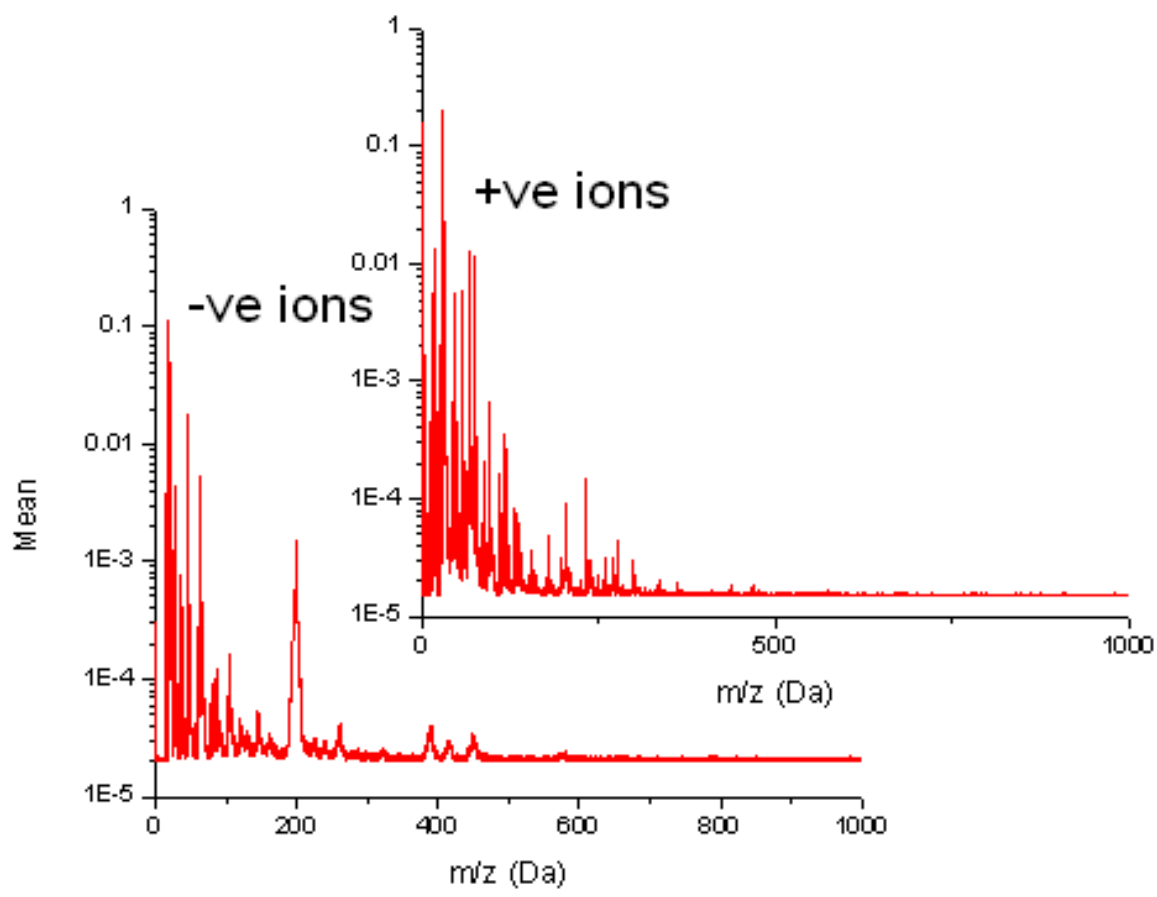

Figure 1 Femtosecond laser ablation spectra showing yields of desorbed positive and negative charged ions from ablated $\mathrm{Au}_{7} \mathrm{Cu}_{5} \mathrm{Al}_{4}$. The yields are expressed in terms of the mean number of ions per laser pulse. 


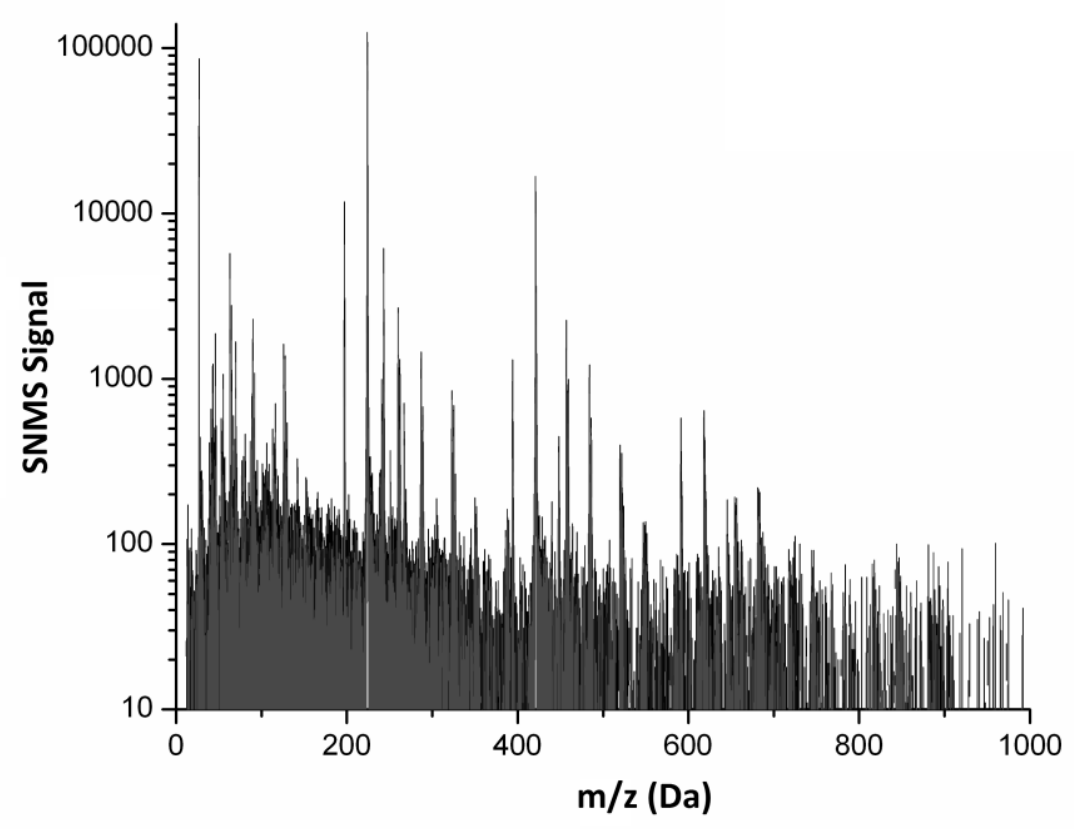

Figure 2 SNMS spectrum of spangold irradiated with $15 \mathrm{keV} \mathrm{Ar}^{+}$. The yields are expressed in terms of the mean number of ions per laser pulse. 


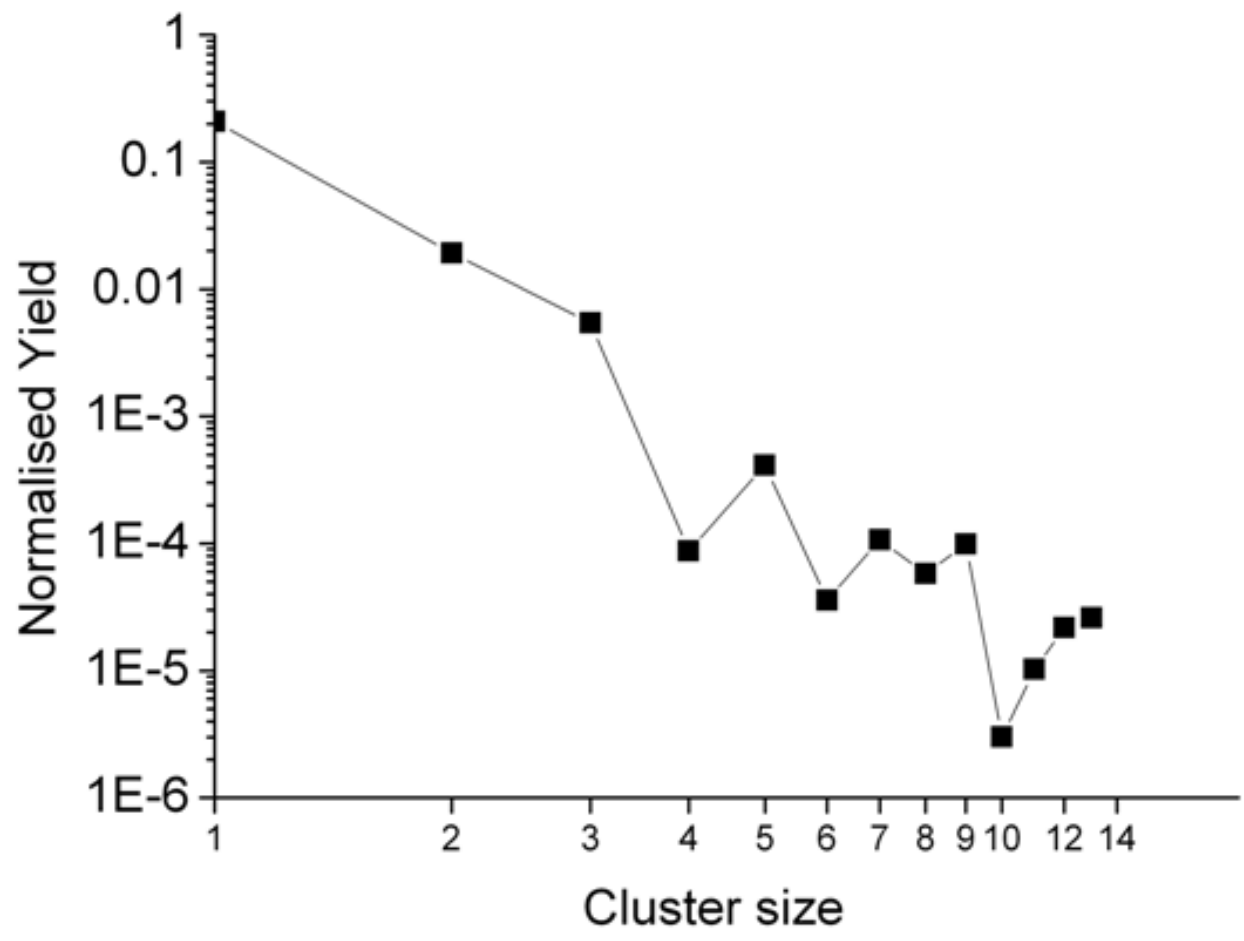

Figure 3 Yield of $\mathrm{Cu}_{n}{ }^{+}$clusters laser ablated from a copper target 


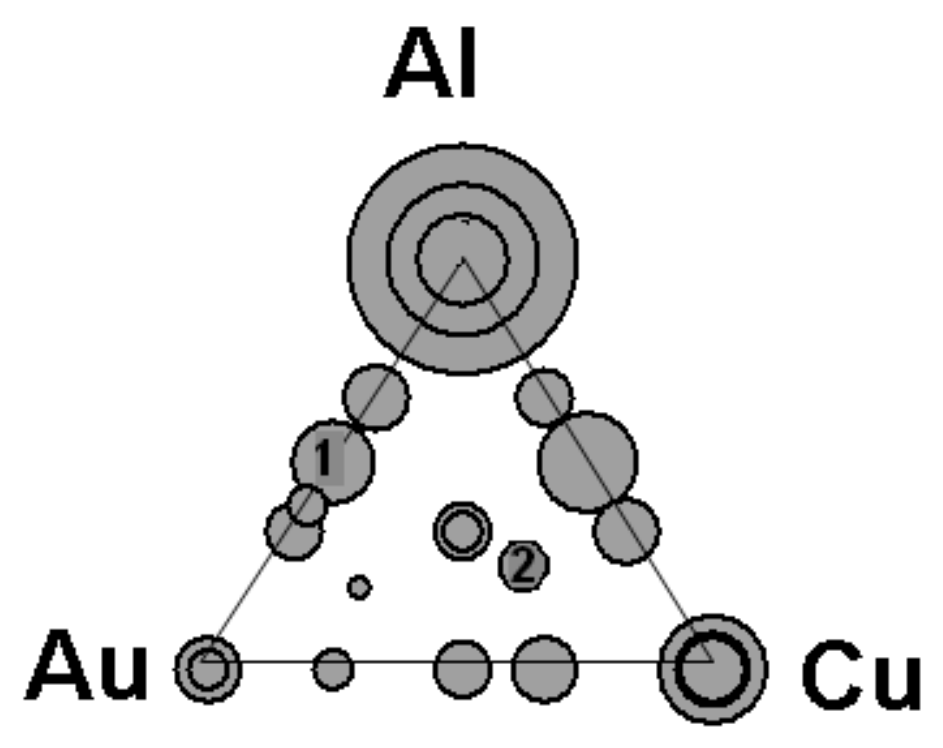

Figure 4 The intensity of positive clusters $(n<6)$ laser ablated for spangold as a function of cluster composition. The diameters of the circles represent $\mathrm{I}^{0.25}$ where $\mathrm{I}$ is the scaled cluster intensity as described in the text. The concentric circles at the triangle vertices represent elemental clusters whereas the other clusters are mixed with distance to the vertex related to the composition. For example, the cluster labeled " 1 " is AuAl, while cluster labeled " 2 " is $\mathrm{Cu}_{2} \mathrm{AuAl}$. 


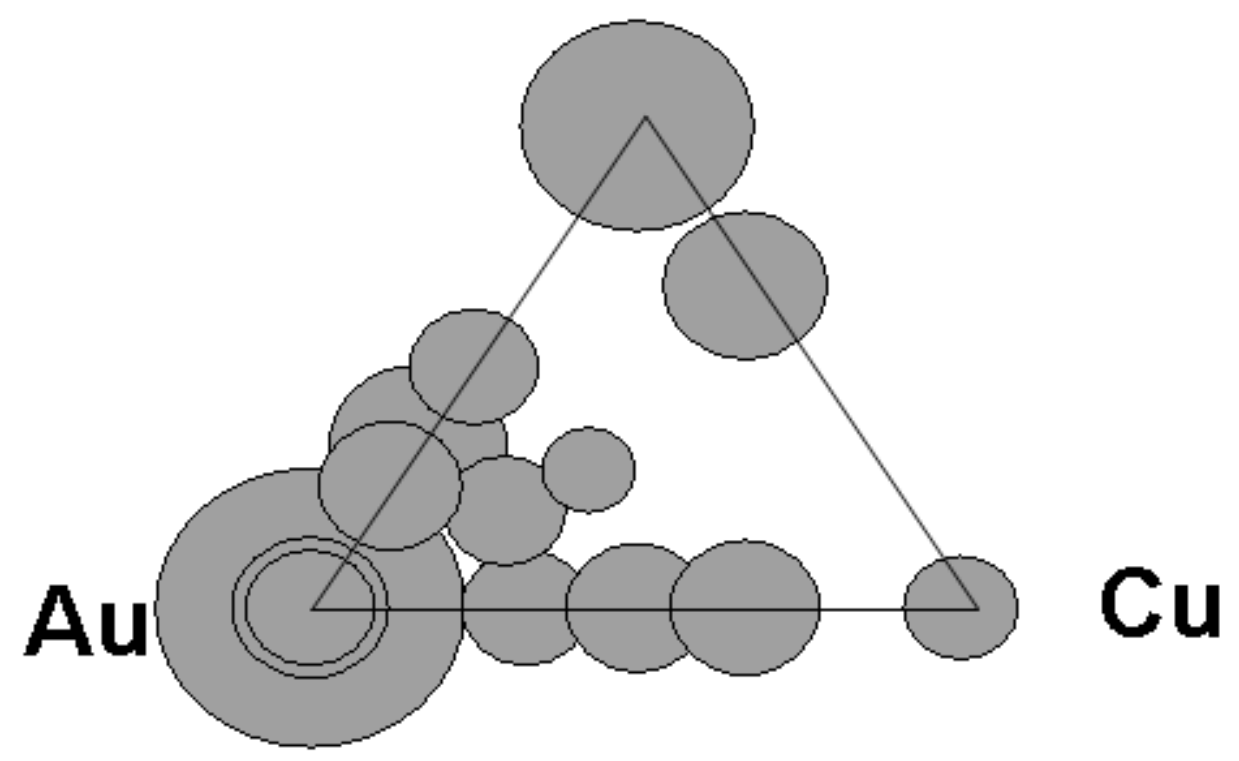

Figure 5 The relative intensity of negative clusters $(n<6)$ ablated from spangold as a function of cluster composition. The data is presented in the same way as in figure 4. 


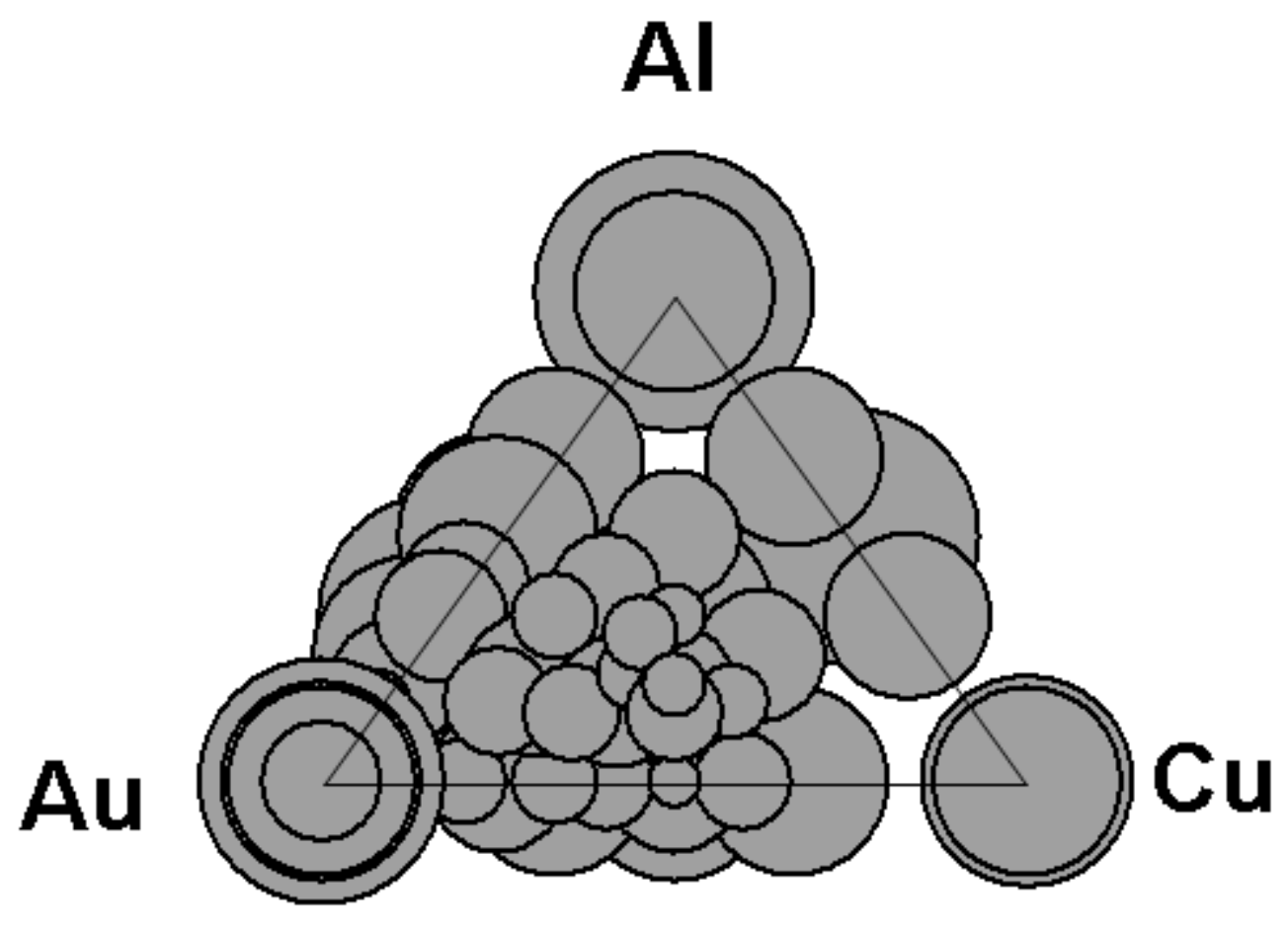

Figure 6 The relative intensity of positive clusters sputtered from spangold and detected by SNMS. The data is presented in the same way as in figure 4 . 


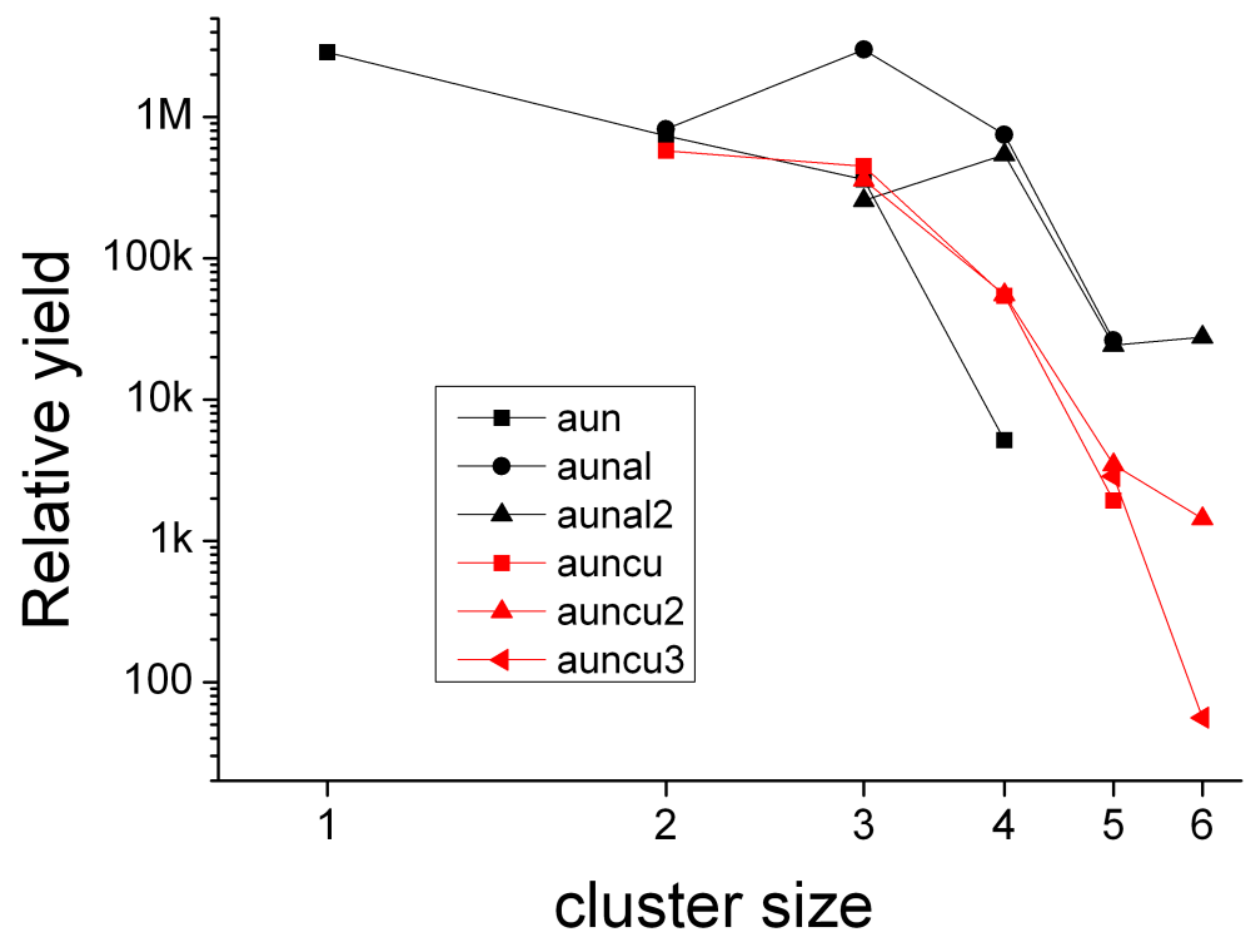

Figure 7 The relative signals from 2 element clusters sputtered from spangold and measured by SNMS. The signals have been scaled by the factor $\mathrm{P}(\mathrm{x}, \mathrm{y}, \mathrm{z})$ 


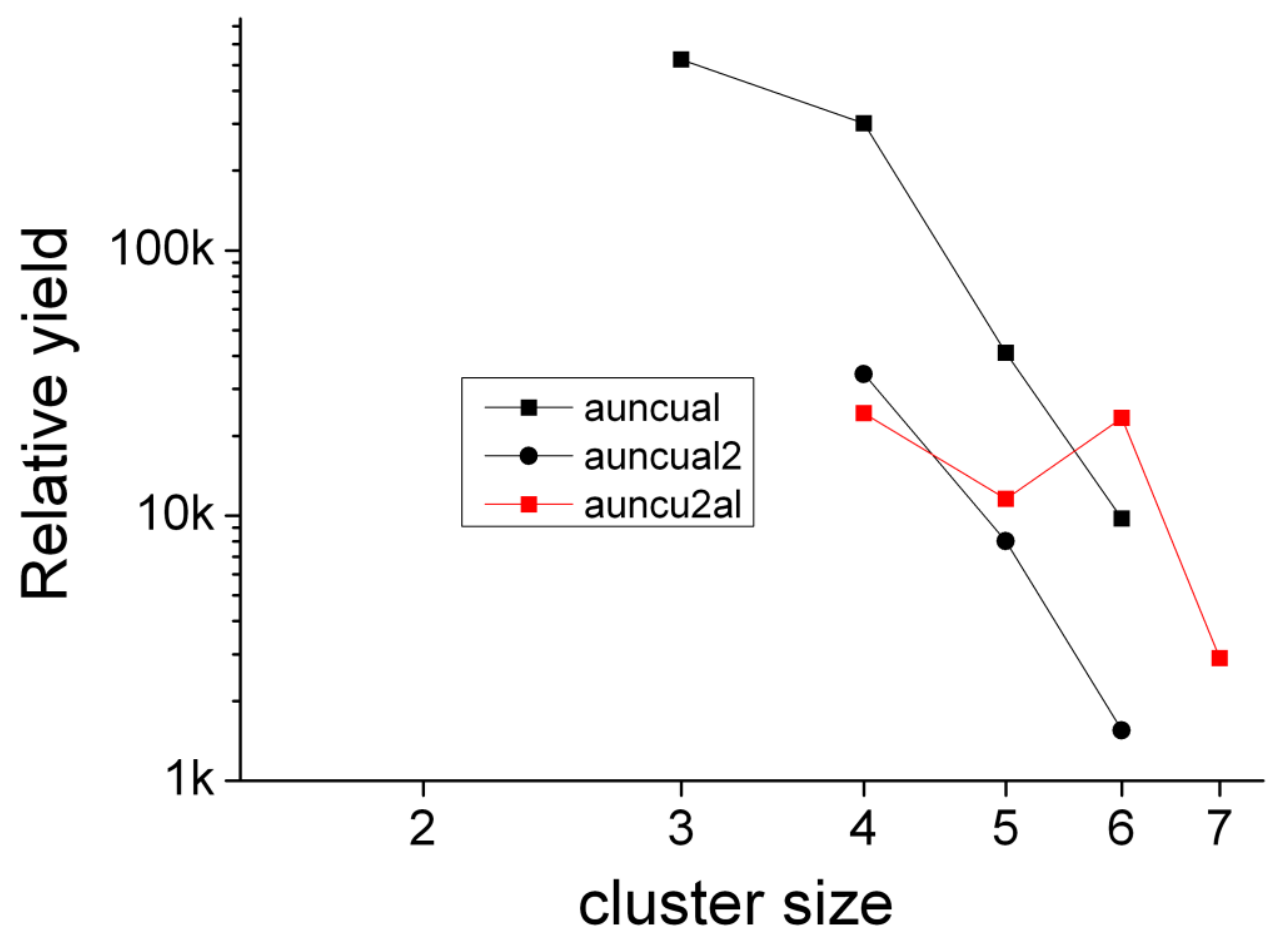

Figure 8 The relative signal from 3 element clusters sputtered from spangold and measured by SNMS. 